\title{
Acute Osteochondral Fractures in the Lower Extremities - Approach to Identification and Treatment
}

\author{
M.E. Pedersen ${ }^{1}$, M.P. DaCambra ${ }^{2}$, Z. Jibri ${ }^{3}$, S. Dhillon ${ }^{3}$, H. Jen ${ }^{3}$ and N.M. Jomha ${ }^{* 1}$ \\ ${ }^{I}$ Division of Orthopaedic Surgery, Department of Surgery, University of Alberta, Edmonton, Canada \\ ${ }^{2}$ CF Health Services Centre, Ottawa, Canada \\ ${ }^{3}$ Department of Radiology \& Diagnostic Imaging, University of Alberta, Edmonton, Canada
}

\begin{abstract}
Chondral and osteochondral fractures of the lower extremities are important injuries because they can cause pain and dysfunction and often lead to osteoarthritis. These injuries can be misdiagnosed initially which may impact on the healing potential and result in poor long-term outcome. This comprehensive review focuses on current pitfalls in diagnosing acute osteochondral lesions, potential investigative techniques to minimize diagnostic errors as well as surgical treatment options. Acute osteochondral fractures are frequently missed and can be identified more accurately with specific imaging techniques. A number of different methods can be used to fix these fractures but attention to early diagnosis is required to limit progression to osteoarthritis. These fractures are common with joint injuries and early diagnosis and treatment should lead to improved long term outcomes.
\end{abstract}

Keywords: Chondral injuries, lower extremity, osteochondral fractures, pathophysiology, osteoarthritis prevention, treatment.

\section{INTRODUCTION}

Injuries on the articular surface of a joint are commonly called chondral or osteochondral fractures but may also be known as transchondral fractures. An osteochondral fracture is considered an injury that damages the cartilage and underlying subchondral bone. Alternatively, a chondral fracture involves only the cartilage without penetration through the subchondral bone. Osteochondral/chondral fractures are related to trauma and may present acutely. However, they are often initially missed, being misdiagnosed as a pure soft tissue injury, and present as chronic lesions. Most of the literature to date focuses on chronic lesions and potential strategies to stimulate repair or regeneration of cartilage. This review will focus on osteochondral lesions (OCLs) that are diagnosed acutely.

Osteochondritis dissecans is a term that was coined by Konig in 1887 to describe the loose bodies that he found in the knee joint [1]. Konig concluded that the etiology of these lesions could be severe trauma with enough force to fracture the joint surface. Alternatively, lesser degrees of trauma can contuse the bone and cause an area of necrosis that allows the joint surface to separate, or, in cases of no trauma, spontaneously necrose [1]. Despite much debate surrounding the term, "osteochondritis dissecans" now is used to describe an area of necrosis of the subchondral bone which may or may not have associated separation of the overlying cartilage $[1,2]$ and will not be the focus of this review.

*Address correspondence to this author at the 2D2.32 WMC Department of Surgery, University of Alberta Hospital, 8440-112St, Edmonton, T6G 2B7, Canada; Tel: 1780407 2816; Fax: 1780407 2819;

E-mail:njomha@ualberta.ca
Attention to osteochondral/chondral fractures is important because these lesions may cause the joint to degenerate into osteoarthritis because articular cartilage has limited potential for self-repair. This may be a greater issue in weight bearing joints. While osteochondral fractures are common in the shoulder (known as Hill Sachs lesions) and have also been reported in the distal humerus, distal radius and wrist [3-6], the progression to arthritis may not be as common, rapid or disabling as in lower extremity joints. In order to minimize the progression to arthritis, it is important to identify and treat osteochondral/chondral fractures early; however, little has been written about the diagnosis and management of acute osteochondral/chondral fractures.

Acute osteochondral fractures have been best studied in pediatric populations. The surgical techniques discussed may be similar in adult populations; however, articular cartilage maturity corresponds with skeletal maturity and physeal closure so pediatric injuries may respond differently. This will be highlighted in the treatment section.

The purpose of this paper is to review the literature regarding acute osteochondral/chondral fractures of the lower extremities providing a review of the anatomy and cellular biology of cartilage with a discussion of healing potential. The term "osteochondral fracture" will be used in this paper to identify lesions which involve traumatic injury to a focal area of articular surface with the underlying subchondral bone. If the lesion is predominantly cartilaginous it may alternatively be called a chondral fracture. The difference between these fractures will be highlighted by the need for different imaging modalities in each case and also in the proposed treatment algorithm. 


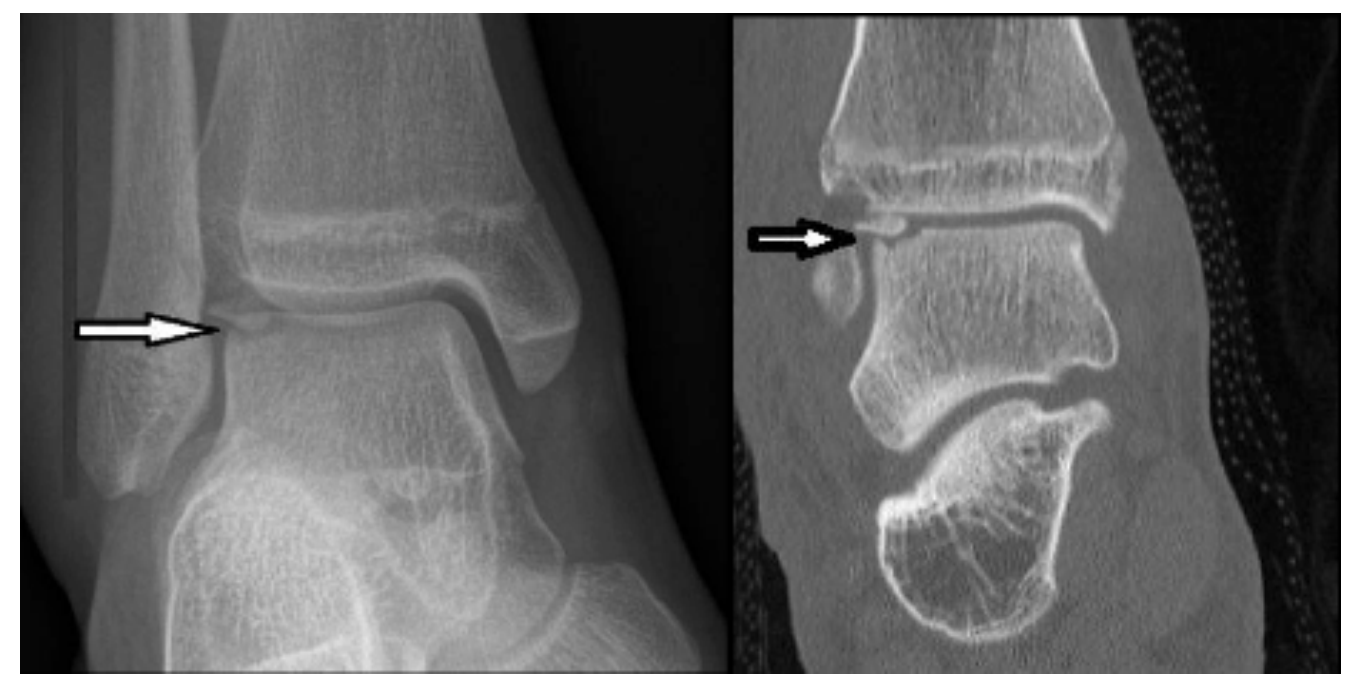

Fig. (1). Radiograph and CT scan demonstrating an osteochondral fracture of the lateral aspect of the talar dome (arrows). It can be seen on the CT image that the fragment has rotated 180 degrees and the smooth subchondral bone surface covered by cartilage is inverted and the fracture surface exposed. This can occur with severe ankle sprains.

\section{INCIDENCE AND PRESENTATION}

An association exists between joint instability and osteochondral lesions because abnormal joint motion causes shearing, rotatory or impaction forces that may create the lesions [7]. The association of osteochondral/chondral fractures with joint injury/sprain is intuitive. For example, in the ankle joint, osteochondral/chondral fractures of the talus may be related to ankle sprains and dislocations (Fig. 1). In the knee, osteochondral injuries to the femoral condyles and patellar facets are relatively common with injuries such as patellar dislocations. And in the hip, osteochondral injuries are most often associated with hip dislocation. The true incidence of osteochondral/chondral fractures in the lower extremity is difficult to determine due to a lack of defined symptoms and radiographic findings at the time of injury.

One population that has been well studied is the military. In a study on an active military population, Orr et al. reported a yearly incidence of initial diagnoses of osteochondral lesions of the talus at 27/100,000 military personnel [8]. Unfortunately, this was a retrospective review based on diagnostic coding so, while they were able to suggest important demographic trends such as an increased incidence with age, they were unable to determine time from injury to diagnosis [8]. Previously, Coltart had studied 25,000 acute fractures and dislocations sustained by a military population during World War II, and found that there were 228 injuries to the talus [9]. He classified these as isolated fractures, fracture-dislocations, pure dislocations and miscellaneous injuries. Of the 228 injuries, 56 were osteochondral fractures (defined as "chip and avulsion fractures") for an incidence of $0.25 \%$ of all talar injuries or approximately 2/10,000 of all acute injuries [9].

Acute osteochondral fractures have also been described with malleolar ankle fractures. Sorrento found a 38\% incidence of lateral talar dome lesions in a random sample of 50 patients undergoing surgical fixation of malleolar ankle fractures [10]. More recent arthroscopic assessments of patients at the time of open reduction internal fixation has shown cartilage damage in up to $79 \%$ [11-14]. Further, there is a higher incidence of osteochondral fractures with more proximal fibular fractures (Weber C) [11]. This is reflective of the ligamentous injury associated with these fractures.

Purely ligamentous injuries are generally cited as the primary etiology of osteochondral/chondral fractures in the ankle. Bosien et al. were the first to report osteochondral fractures with ankle sprains in their study of a group of college men [15]. They found radiographic evidence of nine cortical avulsion fractures in 133 sprains for an incidence of $6.5 \%[15]$.

The mechanism of transchondral fractures of the talus were initially studied by Berndt and Harty [16]. In their cadaver study they found that these fractures occurred with an inversion force in either plantar flexion or dorsiflexion often combined with rotation. With a dorsiflexed ankle, inversion caused the lateral border of the talar dome to abut the fibula, the lateral ligaments to rupture and eventually the talus to rotate leading to a shearing force that damaged the lateral talar dome. In a plantar flexed ankle, the talus is slightly anterior due to the inversion and internal rotation force and thus the posteromedial talar dome is fractured.

In a cadaveric study of osteochondral fractures in the knee, Kennedy et al. found that most lesions were to the medial condyle occurring with either knee extension and lateral rotation or knee flexion with medial rotation [17]. Tibial plateau lesions occurred with knee extension and medial rotation (to the medial plateau) or knee flexion and lateral rotation (to the lateral plateau) [17]. This suggests that when ligament constraints of the knee are lost and force is exerted across the joint, stress to the cartilage may lead to transchondral fractures.

The incidence of knee ligament injuries is approximately $1 \%$ [18]. Most of these are anterior cruciate ligament (ACL) injuries which account for more than $45 \%$ [19]. With these injuries, a valgus stress causes a shearing force across the joint and usually leads to a bone bruise and cartilaginous damage to the femoral condyle. The incidence of osteochondral fractures with ACL injuries may be as high as $80 \%[20,21]$. 
The second most common cause of hemarthrosis to the knee, after ACL injury, is patellar dislocation [22] with an incidence of osteochondral fracture in approximately $70 \%$ of patients [23-25] (Fig. 2). With dislocation, the patella usually translates laterally causing a shearing force to the medial patellar facet as it moves against the lateral femoral condyle. MRI studies have shown that with lateral patellar dislocations, the incidence of osteochondral fractures is between $40 \%$ and $78 \%$ [23, 26-29].

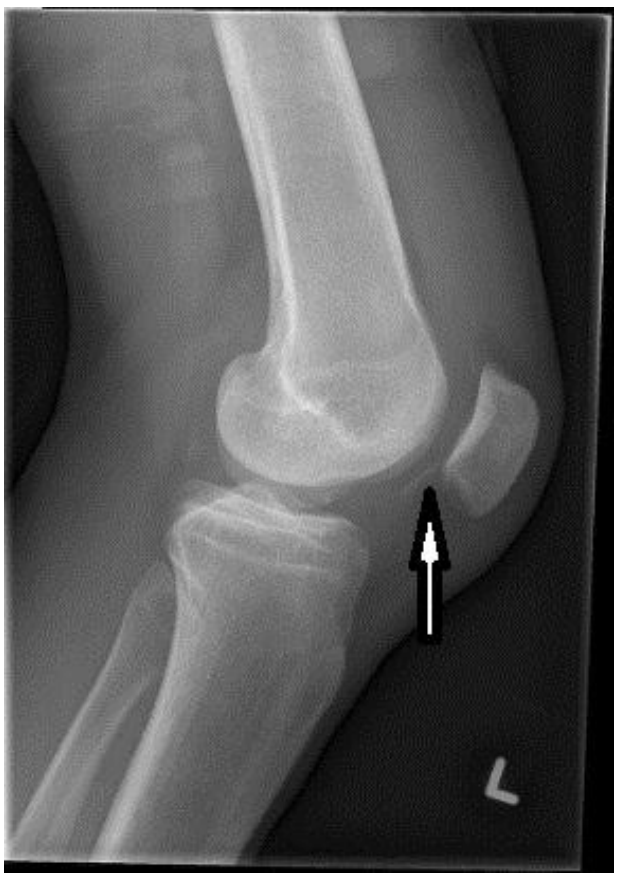

Fig. (2). Osteochondral fracture of the lateral femoral condyle after a patellar dislocation. Note the thin flake of bone at the tip of the arrow. Typically, there is a large fragment of articular cartilage attached to this bone that could be reattached and expected to heal.

There are other intraarticular injuries to the knee that cause hemarthrosis and may be associated with osteochondral fractures. Studies of patients with hemarthroses of the knee report an incidence of articular cartilage lesions as identified on arthroscopy of up to $20 \%$ $[30,31]$. Terry et al. looked retrospectively at isolated osteochondral fractures in the knee and found an incidence of $4 \%$ in acute knee injuries and noted that they were all full thickness lesions that generally happened with a hyperflexion injury [32].

Minor subluxation in the knee joint may damage the joint surface because of its unconstrained nature. The congruity of a normal hip protects the joint so generally a dislocation is required to inflict sufficient damage that is associated with osteochondral fractures $[33,34]$. In a study of hip dislocations, Epstein found that 134 of 151 patients requiring open reduction had a fragment in the joint that was removed but had been too small to visualize on plain films [35]. In a more recent study of arthroscopic findings after traumatic hip dislocation, all 14 patients had evidence of a chondral fracture, 11 of which were loose osteochondral fractures [36] (Fig. 3).

Osteochondral lesions may also be due to a "lateral impact injury" which occurs when there is direct trauma to the greater trochanter $[37,38]$. The greater trochanter has less ability to absorb forces due to the lack of soft tissue between the bone and skin $[38,39]$. At the time of impact the force is transferred to the joint surface and the shearing force may damage the chondral or osteochondral surface $[37,38]$.

In any joint, acute lesions are difficult to diagnose as symptoms are not specific and often are masked by injuries to surrounding tissues. The immediate disability can be minor or related to ligamentous injury or other intra-articular pathology $[40,41]$ or over-shadowed by more obvious and significant injuries like malleolar fractures. Pain is the most common symptom. The pain experienced from symptomatic lesions is usually exacerbated during or after weight bearing activities. If there is a loose fragment, there may be associated mechanical symptoms of locking or catching as the fragment moves around the joint. Typically there is swelling with decreased range of motion due to swelling and pain.

\section{DIAGNOSTIC IMAGING EVALUATION}

The goals of imaging osteochondral lesions (OCLs) are: to confirm clinical suspicion for the lesions, to assess extent of the lesion, to look for any imaging signs of instability, and to assess lesion progression [42]. Standard initial investigation after an acute joint injury includes the plain

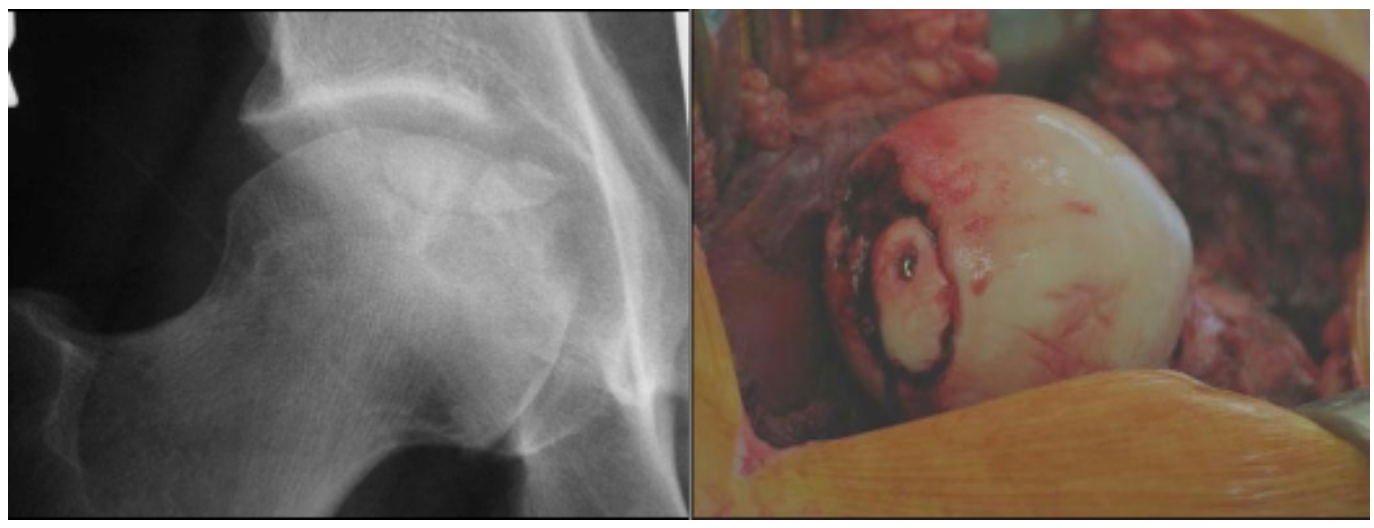

Fig. (3). Osteochondral fracture of the femoral head that required debridement and fixation. Figure on left shows a round central femoral head lesion while the figure on the right shows the femoral head after hip disarticulation and fixation of a portion of the fragment with one screw. 


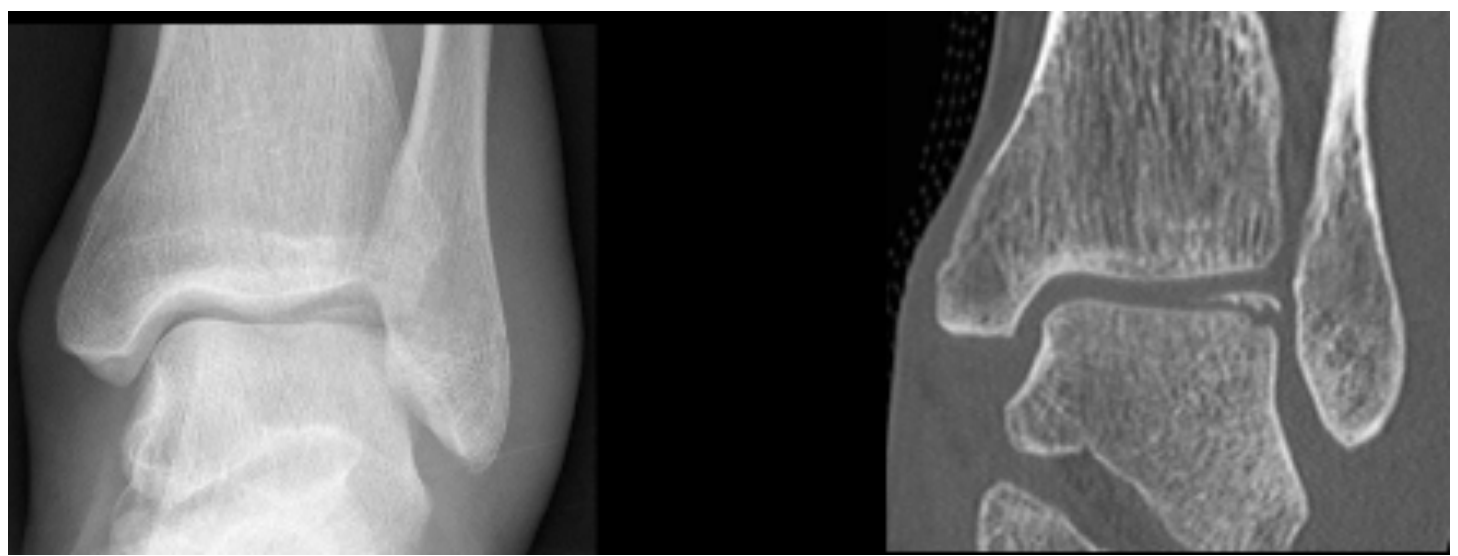

Fig. (4). 24 year old male patient with an acute ankle twisting injury. A) AP plain radiograph of the ankle demonstrating a displaced osteochondral fracture fragment at the lateral talar dome. B) Coronal CT image providing further details about the exact size of the fragment and the donor site.

radiograph. Specific radiographs to the ankle joint would be AP, mortise and lateral ankle views. A standard series of radiographs for the knee usually includes AP, lateral, oblique, and if possible, skyline view of the patella. In the acute setting, these radiographs may be non-weight bearing but if pain permits, weight-bearing radiographs should be obtained. For the hip, a series of radiographs usually includes an AP of the pelvis as well as AP and lateral views of the affected hip. Osteochondral fractures are often difficult to visualize because, while a large articular cartilage fragment may be detached, the associated bony fragment may be small [7] (Fig. 4). In the talus, it has been shown that $69 \%$ of lesions may be detected on radiograph $[43,44]$. At the knee, the diagnostic feature of a femoral OCL is a thin wafer of radiodense subchondral bone, irregular bony contour or bony fragmentation [43]. A standard knee radiograph series identified the OCL in only $32 \%$ of cases noted arthroscopically [24]. This is consistent with the finding that up to $60 \%$ of lesions are missed on initial presentation after patella dislocation [45]. In the hip joint, most lesions are missed on the plain radiograph [34]. McCarthy et al., have shown that $67 \%$ of loose bodies identified arthroscopically in the hip joint cannot be visualized on conventional radiographs [46].

Due to the previously noted factors, OCLs often require further evaluation with other imaging modalities. These would include computed tomography (CT), magnetic resonance imaging (MRI) and bone scintigraphy. MRI and CT are superior to radiography in the detection of OCLs [47]. CT provides high resolution images that are capable of detecting and delineating small osteochondral fragments (Fig. 4). Moreover, CT arthrography, which involves injecting iodinated contrast into the joint, has the added advantage of demonstrating small displaced chondral fragments that are usually not visible on the standard CT. However, CT lacks the ability to demonstrate bone marrow edema [48]. MRI has different sequences providing information based on the signal elicited by each technique (See Table 1). Short tau inversion recovery "(STIR) sequence is the primary "localizer" of the lesion" in acute injury as it is highly sensitive for edema [43]. MRI findings suggestive of an acute osteochondral fracture are an acute fracture plane, joint effusion and extensive bone marrow edema [48].

MRI can define the extent of articular cartilage involvement (Fig. 5). MRI can detect femoral chondral lesions with sensitivity and specificity of $86 \%-93 \%$ and $72 \%-88 \%$, respectively, and acetabular lesions with $91 \%$ $93 \%$ sensitivity and $75 \%-85 \%$ specificity [49]. It was shown that MRI has $86 \%$ sensitivity and $97 \%$ specificity in identifying hyaline cartilage defects in the knee [50]. One study has demonstrated that OCLs of the talar dome can be evaluated on MRI with $95 \%$ sensitivity and $100 \%$ specificity [51]. In another study comparing the diagnostic accuracy of MRI to that of CT for detecting talar OCLs, MRI had a higher sensitivity than CT (96\% versus $81 \%)$; however, this was not statistically significant. This study showed that both MRI and CT have high specificity for identifying OCLs of the talus (96\% and 99\%, respectively) [47]. MRI has the added advantage of detecting other soft tissue abnormalities

Table 1. Information provided by different MRI sequences.

\begin{tabular}{|c|c|c|}
\hline Sequence & Abbreviation & Comments \\
\hline T 1 weighted Spin Echo & T1wSE & $\begin{array}{l}\text { Fracture lines can be visible as linear low signal against higher signal bone marrow. } \\
\qquad \text { Poor for assessing cartilage surface [48]. }\end{array}$ \\
\hline $\begin{array}{l}\text { T2 weighted Turbo Spin } \\
\text { Echo with Fat suppression }\end{array}$ & T2wTSE FS & Allows sharper contrast between relative higher signal cartilage and lower signal bone marrow [51] \\
\hline $\begin{array}{c}\text { Short Tau Inversion } \\
\text { Recovery }\end{array}$ & STIR & $\begin{array}{l}\text { High sensitivity for edema [43]. } \\
\text { Fluid is bright signal allowing demonstration of defects in cartilage. } \\
\text { Less effective in thinner cartilage (talus) [43]. }\end{array}$ \\
\hline
\end{tabular}



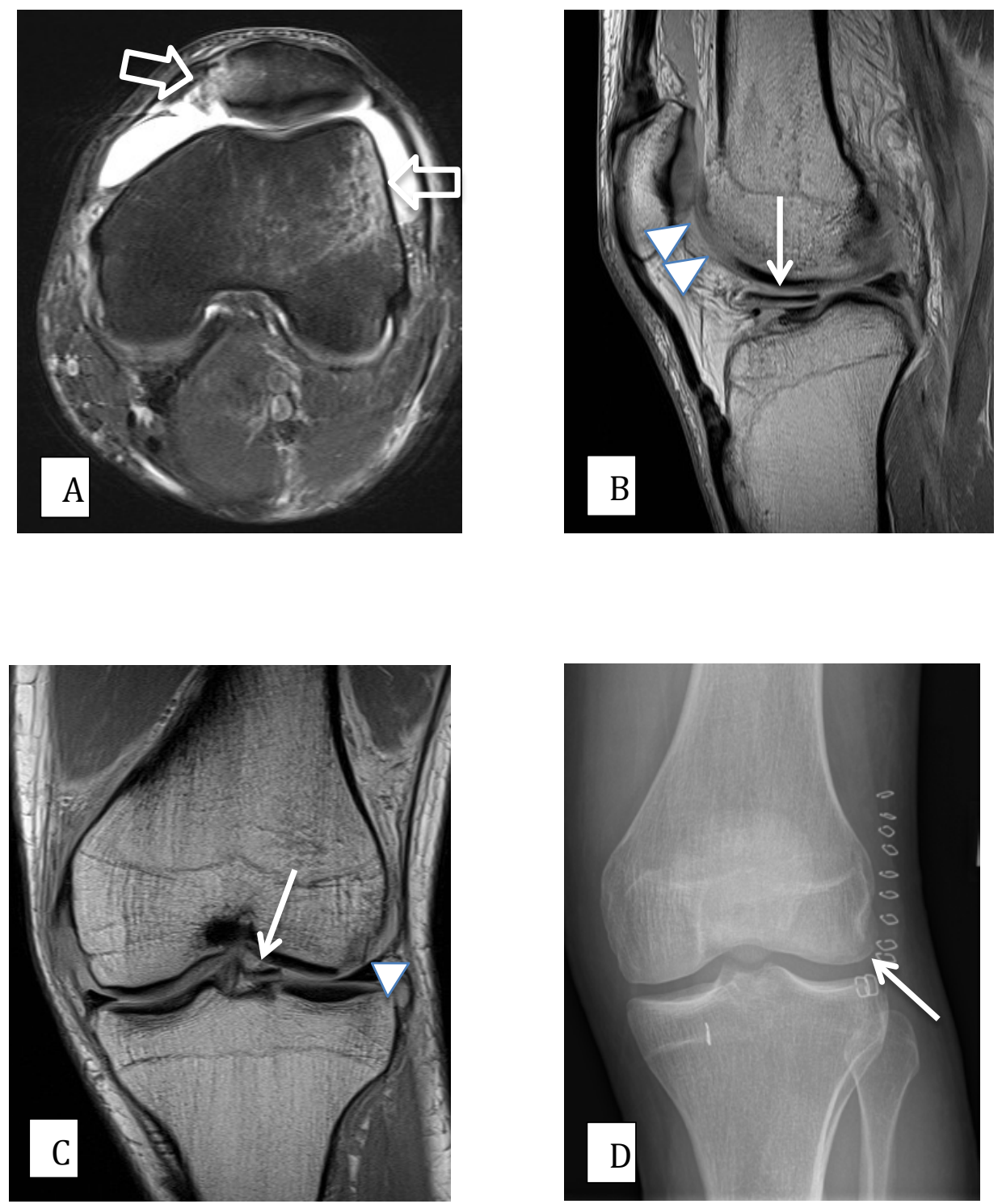

Fig. (5). 27 year old male patient with knee pain following an acute rotational valgus injury. A) Axial PD (proton density) fat saturated MR image, demonstrating edema (high signal) on the outer aspect of the lateral femoral condyle and at the inferomedial aspect of the patella, signifying a recent transient lateral patellar dislocation (open arrows). B) and C) sagittal and coronal PD MR images demonstrating a displaced and medially migrated osteochondral fracture fragment (arrows). The donor site from the lateral femoral condyle is also clearly shown (arrow heads). D) Post-surgical AP radiograph of the knee, demonstrating that the osteochondral fragment has been surgically reduced and fixed into an anatomic position (arrow).

that are often associated with osteochondral injuries. This is important, for example, in those patients with ankle "sprain" injuries, where OCLs can be associated with ligament and tendon abnormalities that can be collectively responsible for persistent ankle pain and instability [52].

MRI can be used to evaluate the stability of the OCL, which is an important factor in planning subsequent management. The classic MRI sign of instability is the presence of fluid signal interposed between the OCL and the parent bone. Other signs that can be suggestive of instability include the presence of "cystic change at the donor site" (late change), "extensive bone marrow edema" at the donor bone disproportionate to the recent injury, and "interval collapse of the articular surface" [53]. The presence of contrast between the fragment and the underlying bone can be used as an indicator for instability $[54,55]$. Thus, both MR and
CT arthrography can be used to assess instability and to provide more accurate staging of the OCL than nonarthrographic imaging.

In the setting of a significant acute injury, the radiograph needs to be scrutinized for the presence of an OCL. Close attention needs to be given to the locations where these lesions are more prevalent, for example the talar dome and adjacent to the patellofemoral joint, where osteochondral fracture fragments can often be seen secondary to patellar dislocation [53, 56]. Should an OCL be suspected, CT or MRI can further define the origin and the extent of the lesion. However, we have observed that on MRI, an osteochondral fracture may appear larger than its actual size due to the bone marrow edema possibly making it may be more difficult to plan fixation, if required. If soft tissue injuries (ligament or tendon injuries) are suspected, then 


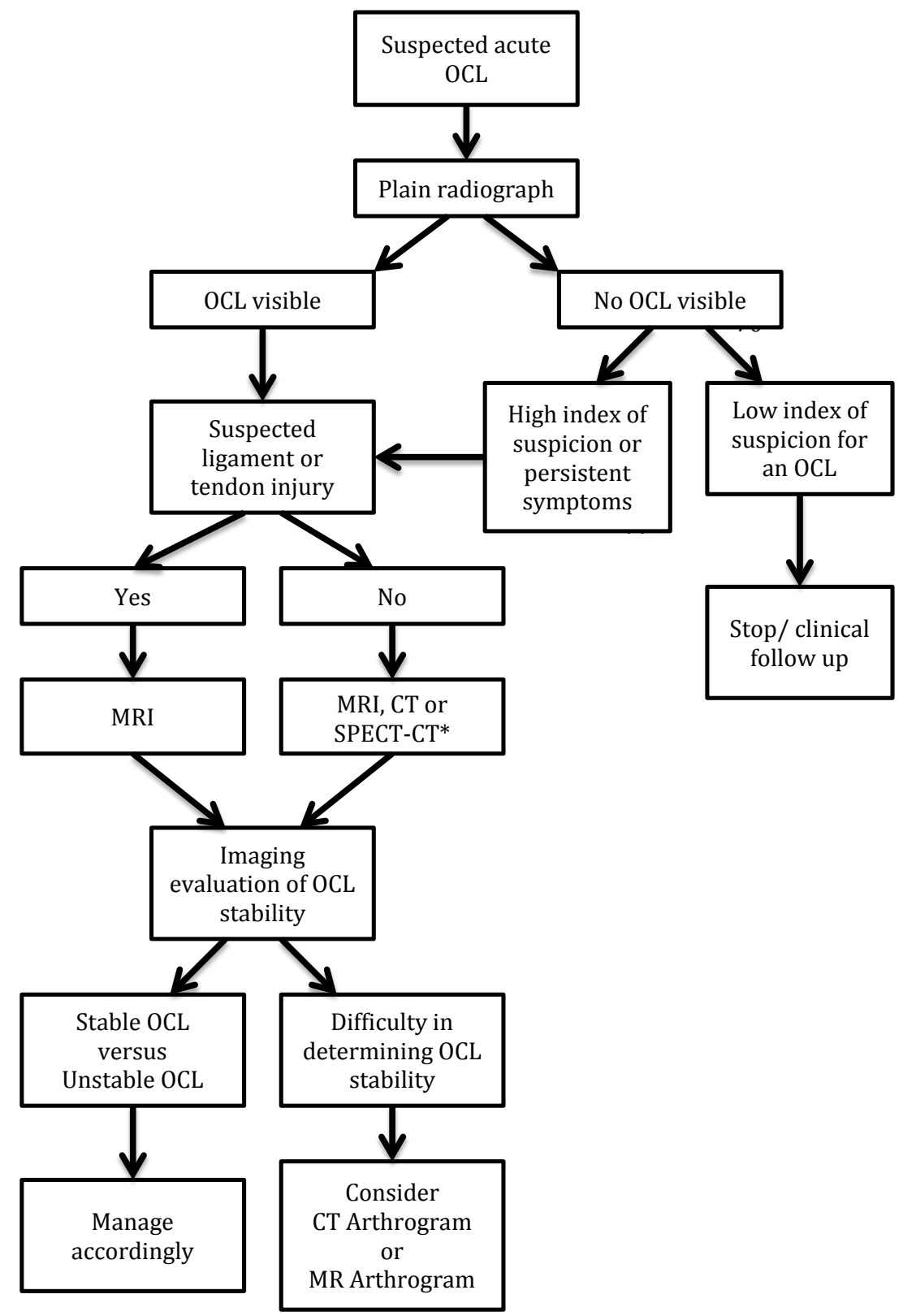

Fig. (6). Suggested imaging pathway in the management of a suspected acute osteochondral lesion of the lower limb. *CT or SPECT-CT should be considered when MRI is contraindicated.

MRI would be a more suitable option in providing a global evaluation of osseous and soft tissue structures (Fig. 6).

Standard bone scans may be useful as an early diagnostic tool due to its high sensitivity as early as 12 hours after injury [43], however; it currently has a limited clinical role in treatment planning due to the lack of sufficient anatomic details. A newer modality that is showing benefit in talar OCL evaluation is SPECT-CT scanning. SPECT (single photon emission computed tomography) scan - CT (computed tomography) is a hardware based fusion of conventional SPECT (tomographic) bone scintigraphy with a conventional diagnostic CT or a low dose "nondiagnostic" CT scan [57]. It involves the performance of a bone scan after intravenous administration of $99 \mathrm{mTc}-\mathrm{MDP}$ tracer. After conventional planar bone scan images are obtained, tomographic (SPECT) bone scan images are then acquired concurrently with a conventional or low dose CT. This dual acquisition is performed simultaneously on the same machine, with the patient in the same body position. This concurrent acquisition allows exact registration of the tomographic images from SPECT bone scan on the CT images. Effectively, this "fusion imaging" modality precisely superimposes a map of metabolic bone reaction over a conventional CT image. SPECT-CT has been used in orthopaedic oncology, trauma and infection and is now starting to find a place in imaging cartilaginous and osteochondral lesions $[8,58]$. It has been studied in the talus $[57,59,60]$ and to a lesser extent in the knee [61]. The clinical utility of this new fusion imaging modality is not yet known. However, some authors suggest that it may subjectively facilitate treatment decisions for OCL [57]. 


\section{MANAGEMENT STRATEGY RATIONALE BASED ON CARTILAGE PHYSIOLOGY}

Acute lesions are often inadvertently managed conservatively due to the difficulty in recognition of the lesion. Given that the true natural history of these lesions is unknown, it may be that some lesions require no treatment. It has been suggested that smaller lesions do not progress to widespread arthritis [62-65]. However, risk factors for progression have not been clearly defined so it is difficult to make recommendations as to which lesions may benefit from benign neglect. Therefore it is prudent to be vigilant for these lesions and, at minimum, institute a non-operative treatment protocol. In order to determine the best treatment, it is important to know the structure of articular cartilage to understand the importance of restoring the cartilage surface, if possible.

The complex nature of the cartilage matrix is extremely difficult to reproduce. Articular cartilage matrix possesses excellent wear characteristics due to its low co-efficient of friction [66]. Its load-bearing properties, resilience and durability are due to the interactions of collagen, proteoglycans and water within the extracellular matrix [62] and this has not been able to be reproduced with all the various available cartilage resurfacing techniques with the exception of cartilage transplantation. A concise description of essential features is presented here.

Articular cartilage is composed of chondrocytes embedded within an extracellular matrix composed mainly of proteoglycans, collagen and water. The chondrocytes within the cartilage matrix constitute approximately $1 \%$ of the tissue volume and maintain the extracellular matrix. These cells receive nutrients and eliminate waste by diffusion and are stimulated by mechanical loads [66-70]. They have limited capacity to divide past skeletal maturity, therefore, over time, the concentration of chondrocytes declines $[71,72]$.

The extracellular matrix (ECM) consists of a dense stable network of collagen fibers which constrain proteoglycan (PG) molecules. Type II collagen is the main collagen type and is uniformly distributed throughout the matrix while the other types are more localized. The PGs make up $5-10 \%$ of the wet weight of the matrix and consist of a protein core with glycosaminoglycan chains (GAG) attached to them [66, 73]. The GAGs exist in three main types - chondroitin sulfate (4- and 6- isomers), keratin sulfate, and dermatin sulfate. PGs contribute to the structural rigidity of the cartilage matrix through three different mechanisms: 1) PGs are highly negatively charged and therefore attract cations giving rise to the Donnan osmotic effect [74-76], 2) PGs are densely packed within the matrix (approximately $1 / 5^{\text {th }}$ of the free solution volume) resulting in strong charge-charge repulsive forces contributing to swelling pressure [77] and 3) PGs are hydrophilic in nature drawing in water molecules [62]. Furthermore, hyaluronate is a GAG that is an anchor for large groups of PG molecules which bind together on one hyaluronic acid molecule to form a large PG aggregate. Aggrecan enhances the immobilization of the PG within the collagenous matrix and may link the cells to the matrix. The binding effect that the collagen has on the PG enables these mechanisms to be extremely effective.
Architecturally, articular cartilage can be divided into four zones - superficial, middle (transition), deep, and calcified. The size and shape of the cells, the size and orientation of the collagen fibers and the content of water and PGs change throughout the zones [62]. The tidemark is $2-5 \mu \mathrm{m}$ thick and may provide a tethering mechanism for the collagen fibers to anchor into the underlying bone and may prevent shear stresses.

Healing after injury depends on the depth of the damage. If the damage shears off the cartilage but does not breach the subchondral bone, then no healing will occur and the defect will remain. If it is large enough (generally considered greater than $1 \mathrm{~cm}$ in diameter), the joint will degenerate into osteoarthritis. Therefore, in pure chondral fractures, the cartilage is unlikely to heal to the underlying bone directly unless some sort of bone resurfacing is attempted. For purely cartilaginous fractures or small lesions that cannot be fixed, debridement and microfracture may be a good option. Microfracture is a technique that is used to produce a fibrocartilage repair surface. It was initially described at the knee $[78,79]$, has been well studied at the ankle [80, 81], and is being investigated at the hip [37]. After the cartilage has been debrided to form a well-contained defect with stable margins, the subchondral bone is perforated to allow bleeding into the defect and a clot forms containing mesenchymal stem cells (Fig. 7). These cells differentiate into chondrocytes and fibrochondrocytes to produce a fibrocartilage that fills the defects.

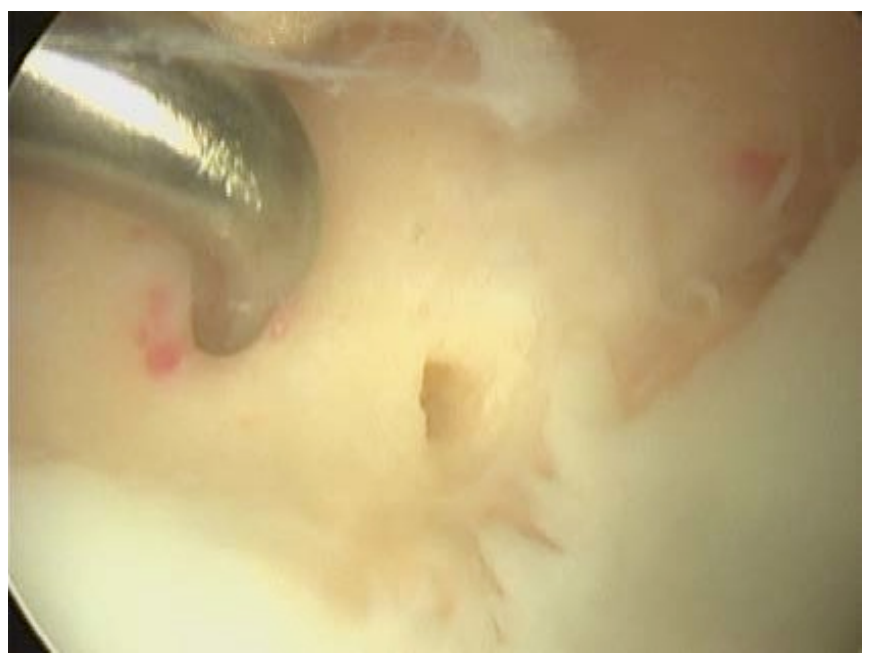

Fig. (7). Arthroscopic view of microfracture technique on the medial femoral condyle. Note how the articular margins have been trimmed back to a stable base, the subchondral bone remains intact and holes in a regular pattern are made through the subchondral bone until the underlying cancellous bone is reached.

If the subchondral bone is breached, this provides access to the blood supply via the bone resulting in the formation of a hematoma. Platelets in the resulting clot that stimulates cytokines and growth factors that create an inflammatory response with vasodilation and the influx of pluripotent cells (mesenchymal stem cells). At approximately 2 weeks, the mesenchymal cells differentiate into chondroblasts and chondrocyte-like cells which produce a matrix of type I and II collagen resembling fibrocartilage [2, 62, 82]. By approximately eight weeks after the injury, the cartilaginous repair tissue has "chondrocytelike cells in a matrix of type II 
collagen, type I collagen, PGs and non-collagenous proteins" [62] which histologically are a mixture of hyaline and fibrocartilage.

Because osteochondral fractures involve the subchondral bone, there is the potential that some of these injuries may heal without intervention. Non-operative treatment of these lesions generally involves a period of non- or restrictedweight bearing and joint protection. In cases of associated injuries to the ligaments or bones, these injuries may also affect the weight bearing status. In cases of isolated osteochondral fractures, there are few guidelines with regard to off-loading the affected joint. The classical rehabilitation protocol after microfracture treatment has been non-weight bearing for 6-8 weeks to allow the clot to form and stabilize within the cartilage defect without unnecessarily compressing it. Early motion is encouraged to facilitate the differentiation of mesenchymal stem cells into chondrocytes and for these chondrocytes to produce primarily collagen type II.

Unfortunately, within one year of microfracture treatment, the new cartilage demonstrates signs of fibrillation and increased water content due to its inferior mechanical properties compared to normal articular cartilage as reviewed by Buckwalter [83]. In addition, if the bone defect is too large, then this type of fibrocartilagenous repair may not fill the defect resulting in mechanical instability and rapid progressive deterioration. Thus, considering the inability to reproduce the complex nature of normal articular cartilage, it is essential to replace and fix the fractured osteochondral fragment back to its original location if at all possible.

Improved imaging protocols should better identify larger lesions that would benefit from acute stabilization in a more timely fashion. In general, larger lesions that are identified acutely should be fixed primarily. This is based on the scientific findings that smaller lesions with a mean size of $309.5 \mathrm{~mm}^{2}$ responded well to conservative treatment and that lesions of a mean size of $436 \mathrm{~mm}^{2}$ failed conservative treatment [84] and larger lesions have a worse prognosis than smaller lesions $[85,86]$. The general principle is to reattach as much of the detached fragments as possible. The fixation can be with headless metallic screws, regular screws with countersunk heads, staples if non-articular bone is available or bio-absorbable non-compressive pins (Fig. 8).
Consideration should be given to remove metallic fixation to prevent long term cartilaginous damage to the opposite surface. Unfortunately, often the procedure to remove these fixation devices causes damage to the articular cartilage [87]. It is more common now to use a bioabsorbable device [88]. It should be reiterated that these fixation techniques require that the fracture is an osteochondral fracture so that the fractured bone can heal to the opposing bone surface.

Results are generally good in the short to medium term $[80,89,90]$. For larger lesions in which the damaged cartilage cannot be replaced, options include auto or allograft osteochondral transplants and autologous chondrocyte implantation with its variants. These procedures are not done in the acute setting and will only be discussed briefly.

Osteochondral autograft transplantation has been utilized for small to medium sized defects by harvesting osteochondral dowels from less essential portions of the same or a different joint. These dowels are then implanted into the defect in an attempt to restore the joint contour and function. Small cores of $6 \mathrm{~mm}$ diameter consisting of the articular cartilage and underlying subchondral bone are harvested and transplanted into the existing defect. If the lesion is larger than $6 \mathrm{~mm}$ diameter (which is most common because lesions smaller than $6 \mathrm{~mm}$ diameter may not need to be treated), then multiple dowels are used and are press-fit resulting in a "mosaic" of dowels termed as mosaicplasty. Osteochondral autografting has produced some good results [91-94] however, dowel alignment is technically difficult and a smooth surface is not guaranteed. Furthermore, there can be variability in the thickness of the cartilage between the donor and recipient sites resulting in an irregular subchondral bone border. The bone portion of the dowels can be an issue as they are susceptible to fracture, especially with $6 \mathrm{~mm}$ dowels, and this could result in unstable fixation and increased production of fibrocartilage between the implanted dowels and neighbouring cartilage.

Osteochondral allografts were established by Gross in the 1970 's as fresh grafts for different disease etiologies including tumours [95] (Fig. 9). Fresh graft, initially denoted as tissue that had been harvested within 72 hours of transplantation, is now used to describe any tissue that has not been frozen or modified prior to transplantation. Longterm results have been very promising $[95,96]$ but
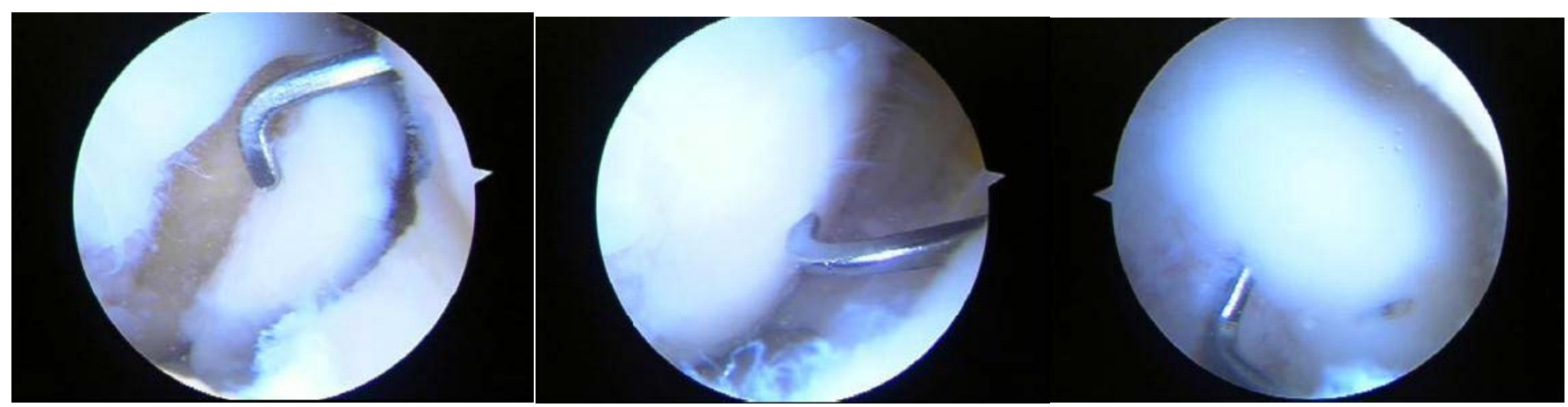

Fig. (8). A series of three arthroscopic images of a medial femoral condylar lesion due to osteochondritis dissecans. The cartilage is intact on the lateral side but the lesion can be mobilized on the cartilage hinge by the probe (left). After curetting of the fibrous tissue off the bone base and removing any dead bone, the lesion is reduced anatomically by the probe (central) and then fixed with bioabsorbable pins arthroscopically (right). One pin can be seen just to the right of the probe and the probe is used to check that the fixation is stable. Although this is a chronic lesion, the fixation principle is valid for acute lesions. 


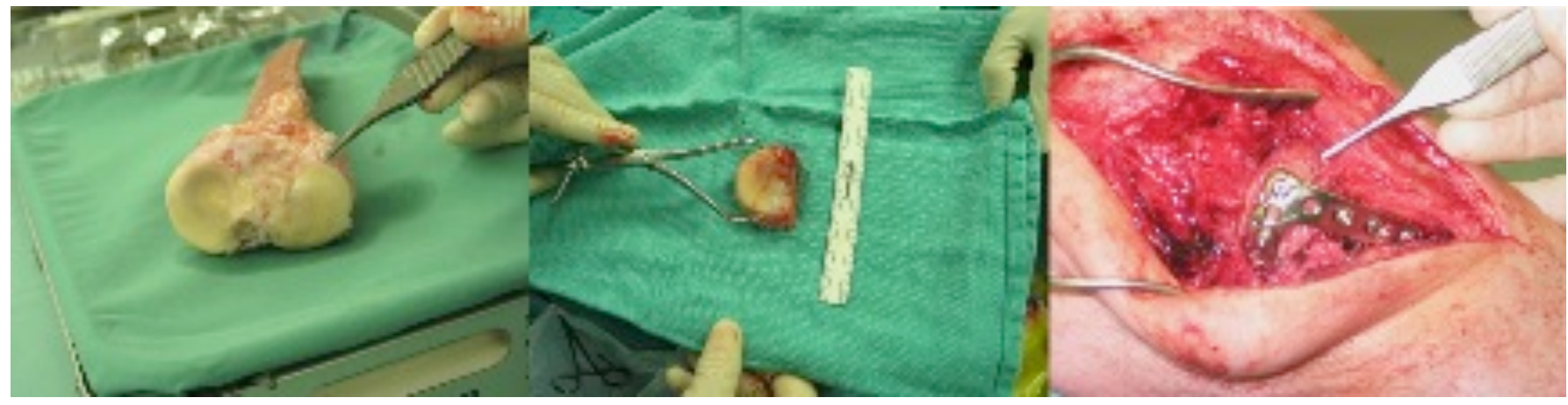

Fig. (9). The left image shows a bulk proximal tibial osteochondral allograft. The appropriate portion of the lateral tibial plateau has been sectioned (center image) and then implanted into the recipient patient and held with a lateral buttress plate (right image).

widespread use of fresh grafts has been limited due to concerns about transmission of infectious diseases, difficulty in size/contour matching, patient and surgical team availability on short notice and lack of donor tissue. To help address these obstacles, a method of hypothermic storage at $4^{\circ} \mathrm{C}$ was developed. Hypothermic storage allows short-term storage (28-42 days) before transplantation.. This time frame does provide increased utility of the technique but studies have shown that cellular deterioration begins after 7-14 days $[97,98]$. With this relatively rapid deterioration of the cells and the technical difficulties of performing the transplant surgery within days of donor harvest due to regulatory clearance issues, the cell viability within hypothermically stored tissue may not be as robust as that in autograft or the original fresh allograft. That said, good results have been reported using both definitions of "fresh" [96, 99-102].

Post-operatively motion is important for providing nutrition to articular cartilage. Some surgeons have advocated the use of continuous passive motion (CPM) [87] but this requires very stable fragment fixation. Typically, the patient will be non-weight bearing on the affected extremity with the joint splinted to prevent shear stress on the repaired fracture site until some fracture healing is expected although early range of motion may be encouraged with stable fixation. Serial radiographs throughout the postoperative period can be used to ensure the joint surface is maintained although these fractures are typically difficult to image because of the small amount of bone available. MRI will provide the most information regarding the cartilage healing and viability.

\section{PROPOSED TREATMENT ALGORITHM}

Injured joint

Physical examination

Appropriate mechanism of injury

Radiographic investigations - see Flow chart 1

Chondral lesion

$<1 \mathrm{~cm}$ diameter - consider non-op tx with possible arthroscopy for removal loose body

$>1 \mathrm{~cm}$ diameter - consider microfracture

Osteochondral lesion
$<1 \mathrm{~cm}$ diameter - consider non-operative treatment with possible arthroscopy for removal loose body

$>1 \mathrm{~cm}$ diameter - consider arthroscopic or open reduction and internal fixation

$>1 \mathrm{~cm}$ diameter with delay in diagnosis (lesion not repairable) - consider osteochondral allograft/autograft or other joint resurfacing techniques (note that these treatment options have not been conclusively proven to prevent osteoarthritis when used inthe acute setting).

\section{CONCLUSION}

Osteochondral/chondral fractures are likely more common than realized. The essential nature of articular cartilage to joint function highlights the importance of treating these injuries early by restoring the joint surface to its pre-traumatic state. If early repair of osteochondral/chondral fractures does not occur, they can develop into chronic lesions with subsequent pain and swelling and, in the long term, result in joint degeneration leading to osteoarthritis, especially in the lower extremity. Maintaining a high index of suspicion and using radiologic techniques at our disposal is important to improve the ability to diagnose these fractures. Once diagnosed, there are a number of options for both acute and chronic lesions that can improve pain and loss of function while potentially delaying or preventing the onset of osteoarthritis. Much more investigation is required into the optimal treatments for various fractures in different joints.

\section{CONFLICT OF INTEREST}

The authors confirm that this article content has no conflict of interest.

\section{ACKNOWLEDGEMENTS}

Declared none.

\section{REFERENCES}

[1] Barrie HJ. Osteochondritis dissecans 1887-1987. A centennial look at Konig's memorable phrase. J Bone Joint Surg Br 1987; 69(5): 693-5.

[2] Bruce EJ, Hamby T, Jones DG. Sports-related osteochondral injuries: clinical presentation, diagnosis, and treatment. Primary Care 2005; 32(1): 253-76. 
[3] Chen WA, Koman LA, Li Z. Arthroscopic treatment of an osteochondral lesion in a child with chronic wrist pain: case report. J Hand Surg 2011; 36(11): 1822-5.

[4] Stamatis ED, Konstantinidou KN. Concomitant, distinct fractures of the capitellum and trochlea separating the whole articular surface of the distal humerus in the coronal plane. Am J Orthop 2007; 36(9): 489-91.

[5] Grant IR, Miller JH. Osteochondral fracture of the trochlea associated with fracture-dislocation of the elbow. Injury 1975; 6(3): 257-60.

[6] Ansah P, Vogt S, Ueblacker P, Martinek V, Woertler K, Imhoff AB. Osteochondral transplantation to treat osteochondral lesions in the elbow. J Bone Joint Surg Am 2007; 89(10): 2188-94.

[7] Milgram JW, Rogers LF, Miller JW. Osteochondral fractures: mechanisms of injury and fate of fragments. AJR Am J Roentgenol 1978; 130(4): 651-8

[8] Orr JD, Dawson LK, Garcia EJ, Kirk KL. Incidence of osteochondral lesions of the talus in the United States military. Foot Ankle Int 2011; 32(10): 948-54.

[9] Coltart WD. Aviator's astragalus. J Bone Joint Surg Br 1952; 34B(4): 545-66.

[10] Sorrento DL, Mlodzienski A. Incidence of lateral talar dome lesions in SER IV ankle fractures. J Foot Ankle Surg 2000; 39(6): 354-8.

[11] Aktas S, Kocaoglu B, Gereli A, Nalbantodlu U, Guven O. Incidence of chondral lesions of talar dome in ankle fracture types. Foot Ankle Int 2008; 29(3): 287-92.

[12] Takao $M$, Ochi $M$, Uchio $\mathrm{Y}$, Naito $\mathrm{K}$, Kono $\mathrm{T}$, Oae $\mathrm{K}$. Osteochondral lesions of the talar dome associated with trauma. Arthroscopy 2003; 19(10): 1061-7.

[13] Hintermann B, Regazzoni P, Lampert C, Stutz G, Gachter A. Arthroscopic findings in acute fractures of the ankle. J Bone Joint Surg Br 2000; 82(3): 345-51.

[14] Loren GJ, Ferkel RD. Arthroscopic assessment of occult intraarticular injury in acute ankle fractures. Arthroscopy 2002; 18(4): 412-21.

[15] Bosien WR, Staples OS, Russell SW. Residual disability following acute ankle sprains. J Bone Joint Surg Am 1955; 37-A(6): 1237-43.

[16] Berndt AL, Harty M. Transchondral fractures (osteochondritis dissecans) of the talus. J Bone Joint Surg Am 1959; 41-A: 9881020.

[17] Kennedy JC, Grainger RW, McGraw RW. Osteochondral fractures of the femoral condyles. J Bone Joint Surg Br 1966; 48(3): 436-40.

[18] Gianotti SM, Marshall SW, Hume PA, Bunt L. Incidence of anterior cruciate ligament injury and other knee ligament injuries: a national population-based study. J Sci Med Sport 2009; 12(6): 6227.

[19] $\mathrm{Ng} \mathrm{AB}$, Bollen SR. Bollen's jig and anterior cruciate ligament reconstruction. J R Coll Surg Edinb 2000; 45(5): 318-20.

[20] Johnson DL, Urban WP, Jr., Caborn DN, Vanarthos WJ, Carlson CS. Articular cartilage changes seen with magnetic resonance imaging-detected bone bruises associated with acute anterior cruciate ligament rupture. Am J Sports Med 1998; 26(3): 409-14.

[21] Lahm A, Erggelet C, Steinwachs M, Reichelt A. Articular and osseous lesions in recent ligament tears: arthroscopic changes compared with magnetic resonance imaging findings. Arthroscopy 1998; 14(6): 597-604

[22] Harilainen A, Myllynen P, Antila H, Seitsalo S. The significance of arthroscopy and examination under anaesthesia in the diagnosis of fresh injury haemarthrosis of the knee joint. Injury 1988; 19(1): 21-

[23] Elias DA, White LM, Fithian DC. Acute lateral patellar dislocation at MR imaging: injury patterns of medial patellar soft-tissue restraints and osteochondral injuries of the inferomedial patella. Radiology 2002; 225(3): 736-43.

[24] Stanitski CL, Paletta GA, Jr. Articular cartilage injury with acute patellar dislocation in adolescents. Arthroscopic and radiographic correlation. Am J Sports Med 1998; 26(1): 52-5.

[25] Sallay PI, Poggi J, Speer KP, Garrett WE. Acute dislocation of the patella. A correlative pathoanatomic study. Am J Sports Med 1996; 24(1): 52-60.

[26] Kirsch MD, Fitzgerald SW, Friedman H, Rogers LF. Transient lateral patellar dislocation: diagnosis with MR imaging. AJR Am J Roentgenol 1993; 161(1): 109-13.

[27] Lance E, Deutsch AL, Mink JH. Prior lateral patellar dislocation: MR imaging findings. Radiology 1993; 189(3): 905-7.
[28] Quinn SF, Brown TR, Demlow TA. MR imaging of patellar retinacular ligament injuries. J Magn Reson Imaging 1993; 3(6): 843-7.

[29] Sanders TG, Paruchuri NB, Zlatkin MB. MRI of osteochondral defects of the lateral femoral condyle: incidence and pattern of injury after transient lateral dislocation of the patella. AJR Am J Roentgenol 2006, 187(5): 1332-7.

[30] Maffulli N, Binfield PM, King JB, Good CJ. Acute haemarthrosis of the knee in athletes. A prospective study of 106 cases. J Bone Joint Surg Br 1993; 75(6): 945-9.

[31] Noyes FR, Bassett RW, Grood ES, Butler DL. Arthroscopy in acute traumatic hemarthrosis of the knee. Incidence of anterior cruciate tears and other injuries. J Bone Joint Surg Am 1980; 62(5): 687-695, 757.

[32] Terry GC, Flandry F, Van Manen JW, Norwood LA. Isolated chondral fractures of the knee. Clin Orthop Relat Res 1988; 234: 170-77.

[33] Laorr A, Greenspan A, Anderson MW, Moehring HD, McKinley T. Traumatic hip dislocation: early MRI findings. Skeletal Radiol 1995; 24(4): 239-45.

[34] Tehranzadeh J, Vanarthos W, Pais MJ. Osteochondral impaction of the femoral head associated with hip dislocation: CT study in 35 patients. AJR Am J Roentgenol 1990; 155(5): 1049-52.

[35] Epstein HC. Traumatic dislocations of the hip. Clin Orthop Relat Res 1973; 92: 116-42.

[36] Philippon MJ, Kuppersmith DA, Wolff AB, Briggs KK. Arthroscopic findings following traumatic hip dislocation in 14 professional athletes. Arthroscopy 2009; 25(2): 169-74.

[37] Khanduja V, Villar RN. Arthroscopic surgery of the hip: current concepts and recent advances. J Bone Joint Surg Br 2006; 88(12): 1557-66.

[38] Byrd JW. Lateral impact injury. A source of occult hip pathology. Clin Sports Med 2001; 20(4): 801-15.

[39] Kelly BT, Williams RJ, 3rd, Philippon MJ. Hip arthroscopy: current indications, treatment options, and management issues. Am J Sports Med 2003; 31(6): 1020-37.

[40] Flick AB, Gould N. Osteochondritis dissecans of the talus (transchondral fractures of the talus): review of the literature and new surgical approach for medial dome lesions. Foot Ankle 1985; 5(4): $165-85$.

[41] O'Donoghue DH. Chondral and osteochondral fractures. J Trauma 1966; 6(4): 469-81.

[42] Griffith JF, Lau DTY, Yeung DKW, Wong MWN. High-resolution MR imaging of talar osteochondral lesions with new classification. Skeletal Radiol 2012; 41(4): 387-99.

[43] Bohndorf K. Imaging of acute injuries of the articular surfaces (chondral, osteochondral and subchondral fractures). Skeletel Radiol 1999; 28(10): 545-60.

[44] Pettine KA, Morrey BF. Osteochondral fractures of the talus. A long-term follow-up. J Bone Joint Surg Br 1987; 69(1): 89-92.

[45] Dainer RD, Barrack RL, Buckley SL, Alexander AH. Arthroscopic treatment of acute patellar dislocations. Arthroscopy 1988; 4(4): 267-71.

[46] McCarthy JC, Busconi B. The role of hip arthroscopy in the diagnosis and treatment of hip disease. Orthopedics 1995; 18(8): 753-6.

[47] Verhagen RA, Maas M, Dijkgraaf MG, Tol JL, Krips R, van Dijk CN. Prospective study on diagnostic strategies in osteochondral lesions of the talus. Is MRI superior to helical CT? J Bone Joint Surg Br 2005; 87(1): 41-6.

[48] Kan HJ. Osteochondral abnormalities: Pitfalls, injuries and osteochondritis dissecans. USA: AARS Categorical Course 2011; pp. 149-52.

[49] Slaughter AJ, Reynolds KA, Jambhekar K, David RM, Hasan SA, Pandey T. Clinical orthopedic examination findings in the lower extremity: correlation with imaging studies and diagnostic efficacy. Radiographics 2014; 34(2): E41-55.

[50] Disler DG, McCauley TR, Kelman CG, et al. Fat-suppressed threedimensional spoiled gradient-echo MR imaging of hyaline cartilage defects in the knee: Comparison with standard MR imaging and arthroscopy. Am J Roentgenol 1996; 167(1): 127-32.

[51] Mintz DN, Tashjian GS, Connell DA, Deland JT, O'Malley M, Potter HG. Osteochondral lesions of the talus: a new magnetic resonance grading system with arthroscopic correlation. Arthroscopy 2003; 19(4): 353-9. 
[52] Jibri Z, Mukherjee K, Kamath S, Mansour R. Frequently missed findings in acute ankle injury. Semin Musculoskelet Radiol 2013; 17(4): 416-28

[53] Naran KN, Zoga AC. Osteochondral lesions about the ankle. Radiol Clin North Am 2008; 46(6): 995-1002.

[54] El-Khoury GY, Alliman KJ, Lundberg HJ, Rudert MJ, Brown TD, Saltzman CL. Cartilage thickness in cadaveric ankles: Measurement with double-contrast multi-detector row CT arthrography versus MR imaging. Radiology 2004; 233(3): 768-73.

[55] Schmid MR, Pfirrmann CWA, Hodler J, Vienne P, Zanetti M. Cartilage lesions in the ankle joint: comparison of MR arthrography and CT arthrography. Skeletel Radiol 2003; 32(5): 259-65.

[56] Capps GW, Hayes CW. Easily missed injuries around the knee. Radiographics 1994; 14(6): 1191-210.

[57] Leumann A, Valderrabano V, Plaass C, Rasch H, Studler U, Hintermann B, Pagenstert GI. A novel imaging method for osteochondral lesions of the talus--comparison of SPECT-CT with MRI. Am J Sports Med 2011; 39(5): 1095-101.

[58] Papathanassiou D, Bruna-Muraille C, Jouannaud C, GagneuxLemoussu L, Eschard JP, Liehn JC. Single-photon emission computed tomography combined with computed tomography (SPECT/CT) in bone diseases. Joint Bone Spine 2009; 76(5): 47480 .

[59] Meftah M, Katchis SD, Scharf SC, Mintz DN, Klein DA, Weiner LS. SPECT/CT in the management of osteochondral lesions of the talus. Foot Ankle Int 2011; 32(3): 233-8.

[60] Wiewiorski M, Pagenstert G, Rasch H, Jacob AL, Valderrabano V. Pain in osteochondral lesions. Foot Ankle Special 2011; 4(2): 92-9.

[61] Hirschmann MT, Davda K, Iranpour F, Rasch H, Friederich NF. Combined single photon emission computerised tomography and conventional computerised tomography (SPECT/CT) in patellofemoral disorders: a clinical review. Int Orthop 2011;35(5): 675-80.

[62] Buckwalter JA. Articular cartilage injuries. Clin Orthop Relat Res 2002; 402: 21-37.

[63] Mankin HJ. The response of articular cartilage to mechanical injury. J Bone Joint Surg Am 1982; 64(3): 460-66.

[64] Campbell CJ. The healing of cartilage defects. Clin Orthop Relat Res 1969; 64: 45-63.

[65] Fuller JA, Ghadially FN. Ultrastructural observations on surgically produced partial-thickness defects in articular cartilage. Clin Orthop Relat Res 1972; 86: 193-205.

[66] Mankin HJ, Mow VC, Buckwalter JA, Iannotti JP, Ratcliffe A. Form and function of articular cartilage. In: Simon SR, Ed. Orthopaedic Basic Science. Chicago: American Academy if Orthopaedic Surgeons 1994; pp. 1-44.

[67] Freeman PM, Natarajan RN, Kimura JH, Andriacchi TP. Chondrocyte cells respond mechanically to compressive loads. J Orthop Res 1994; 12(3): 311-20.

[68] Little CB, Ghosh P. Variation in proteoglycan metabolism by articular chondrocytes in different joint regions is determined by post-natal mechanical loading. Osteoarthritis Cartilage 1997; 5(1): 49-62.

[69] Steinmeyer J, Ackermann B, Raiss RX. Intermittent cyclic loading of cartilage explants modulates fibronectin metabolism. Osteoarthritis Cartilage 1997; 5(5): 331-41.

[70] Suh JK, Baek GH, Aroen A, et al. Intermittent sub-ambient interstitial hydrostatic pressure as a potential mechanical stimulator for chondrocyte metabolism. Osteoarthritis Cartilage 1999; 7(1): 71-80.

[71] Hall AC, Urban JP, Gehl KA. The effects of hydrostatic pressure on matrix synthesis in articular cartilage. J Orthop Res 1991; 9(1): $1-10$.

[72] Kiviranta I, Jurvelin J, Tammi M, Saamanen AM, Helminen HJ. Weight bearing controls glycosaminoglycan concentration and articular cartilage thickness in the knee joints of young beagle dogs. Arthritis Rheum 1987; 30(7): 801-9.

[73] Kuettner KE. Biochemistry of articular cartilage in health and disease. Clin Biochem 1992; 25(3): 155-63.

[74] Maroudas A. Physicochemical properties of cartilage in the light of ion exchange theory. Biophys J 1968; 8(5): 575-95.

[75] Maroudas A. Balance between swelling pressure and collagen tension in normal and degenerate cartilage. Nature 1976; 260: 8089.
[76] Maroudas A, Bayliss MT, Venn MF. Further studies on the composition of human femoral head cartilage. Ann Rheum Dis 1980; 39(5): 514-23.

[77] Khalsa PS, Eisenberg SR. Compressive behavior of articular cartilage is not completely explained by proteoglycan osmotic pressure. J Biomech 1997; 30(6): 589-94.

[78] Steadman JR, Rodkey WG, Rodrigo JJ. Microfracture: surgical technique and rehabilitation to treat chondral defects. Clin Orthop 2001; (391 Suppl): S362-9.

[79] Steadman JR, Miller BS, Karas SG, Schlegel TF, Briggs KK, Hawkins RJ. The microfracture technique in the treatment of fullthickness chondral lesions of the knee in National Football League players. J Knee Surg 2003; 16(2): 83-6.

[80] Doral MN, Bilge O, Batmaz G, et al.. Treatment of osteochondral lesions of the talus with microfracture technique and postoperative hyaluronan injection. Knee Surg Sports Traumatol Arthrosc 2012; 20: 1298-403.

[81] Becher C, Driessen A, Hess T, Longo UG, Maffulli N, Thermann H. Microfracture for chondral defects of the talus: maintenance of early results at midterm follow-up. Knee Surg Sports Traumatol Arthrosc 2010; 18(5): 656-63.

[82] Newman AP. Articular cartilage repair. Am J Sports Med 1998; 26(2): 309-24.

[83] Buckwalter JA. Mechanical injuries of articular cartilage. Iowa Orthop J 1992; 12: 50-57.

[84] Cahill BR. Osteochondritis dissecans of the knee: Treatment of juvenile and adult forms. J Am Acad Orthop Surg 1995, 3(4): 23747.

[85] De Smet AA, Ilahi OA, Graf BK. Untreated osteochondritis dissecans of the femoral condyles: prediction of patient outcome using radiographic and MR findings. Skeletal Radiol 1997; 26(8): 463-7.

[86] Hughston JC, Hergenroeder PT, Courtenay BG. Osteochondritis dissecans of the femoral condyles. J Bone Joint Surg Am 1984; 66(9): 1340-48.

[87] Koeter S, Loon CJM, Susante JLC. Fracture osteochondrale du condyle femoral lateral par luxationde la rotule. Eur J Orthop Surg Traumatol 2005; 16: 268-70.

[88] Wouters DB, Burgerhof JG, de Hosson JT, Bos RR. Fixation of osteochondral fragments in the human knee using Meniscus Arrows. Knee Surg Sports Traumatol Arthrosc 2011; 19(2): 183-8.

[89] Apprich S, Trattnig S, Welsch GH, et al. Assessment of articular cartilage repair tissue after matrix-associated autologous chondrocyte transplantation or the microfracture technique in the ankle joint using diffusion-weighted imaging at 3 Tesla. Osteoarthritis Cartilage 2012; 20(7): 703-11.

[90] Saxena A, Eakin C: Articular talar injuries in athletes: results of microfracture and autogenous bone graft. Am J Sports Med 2007; 35(10): 1680-87.

[91] Hangody L, Kish G, Modis L, Szerb I, Gaspar L, Dioszegi Z, Kendik Z. Mosaicplasty for the treatment of osteochondritis dissecans of the talus: two to seven year results in 36 patients. Foot Ankle Int 2001; 22(7): 552-8.

[92] Hangody L, Dobos J, Balo E, Panics G, Hangody LR, Berkes I. Clinical experiences with autologous osteochondral mosaicplasty in an athletic population: a 17-year prospective multicenter study. Am J Sports Med 2010; 38(6): 1125-33.

[93] Kilic A, Kabukcuoglu Y, Gul M, Ozkaya U, Sokucu S. Early results of open mosaicplasty in osteochondral lesions of the talus. Acta Orthop Traumatol Turc 2009; 43(3): 235-42.

[94] Liu W, Liu F, Zhao W, Kim JM, Wang Z, Vrahas MS. Osteochondral autograft transplantation for acute osteochondral fractures associated with an ankle fracture. Foot Ankle Int 2011; 32(4): 437-42.

[95] Gross AE, Agnidis Z, Hutchison CR. Osteochondral defects of the talus treated with fresh osteochondral allograft transplantation. Foot Ankle Int 2001; 22(5): 385-91.

[96] Aubin PP, Cheah HK, Davis AM, Gross AE. Long-term followup of fresh femoral osteochondral allografts for posttraumatic knee defects. Clin Orthop 2001;(391 Suppl): S318-27.

[97] Williams SK, Amiel D, Ball ST, et al. Prolonged storage effects on the articular cartilage of fresh human osteochondral allografts. J Bone Joint Surg Am 2003; 85-A(11): 2111-20.

[98] Ball ST, Amiel D, Williams SK, et al. The effects of storage on fresh human osteochondral allografts. Clin Orthop Relat Res 2004(418): 246-52. 
[99] El-Rashidy H, Villacis D, Omar I, Kelikian AS. Fresh osteochondral allograft for the treatment of cartilage defects of the talus: a retrospective review. J Bone Joint Surg Am 2011; 93(17): 1634-40.

[100] Adams SB, Jr., Viens NA, Easley ME, Stinnett SS, Nunley JA, $2^{\text {nd }}$. Midterm results of osteochondral lesions of the talar shoulder treated with fresh osteochondral allograft transplantation. J Bone Joint Surg Am 2011; 93(7): 648-54
[101] Hahn DB, Aanstoos ME, Wilkins RM. Osteochondral lesions of the talus treated with fresh talar allografts. Foot Ankle Int 2010; 31(4): 277-82.

[102] Tontz WL, Jr., Bugbee WD, Brage ME. Use of allografts in the management of ankle arthritis. Foot Ankle Clin 2003; 8(2): 361-73, xi.

Received: February 10, 2015

Revised: March 14, 2015

Accepted: March 24, 2015

(C) Pedersen et al.; Licensee Bentham Open.

This is an open access article licensed under the terms of the Creative Commons Attribution Non-Commercial License (http://creativecommons.org/licenses/by-nc/3.0/) which permits unrestricted, non-commercial use, distribution and reproduction in any medium, provided the work is properly cited. 